

\section{A mediação na Educação Infantil: possibilidade de aprendizagem}

\section{Mediation in Early Childhood Education: the possibility of learning}

\author{
Angela do Céu Ubaiara Brito \\ Professora da Universidade do Estado do Amapá, Macapá, Amapá, Brasil. \\ angela.brito@ueap.edu.br - https://orcid.org/0000-0002-4335-8163
}

\section{Tizuko Morchida Kishimoto}

Professora na Universidade de São Paulo, São Paulo, São Paulo, Brasil.

tmkishim@usp.br - https://orcid.org/000-001-7159-0835

Recebido em 02 de janeiro de 2019

Aprovado em 05 de novembro de 2019

Publicado em 17 de dezembro de 2019

\section{RESUMO}

A educação Infantil favorece contexto de aprendizagem para a criança quando possibilita um processo de mediação. A mediação na educação é a intervenção que estabelece relações intermediárias para a aprendizagem. $O$ trabalho trata de um ensaio bibliográfico que discute na obra de Lev Vygotski o processo de mediação na educação e em autores da infância a possibilidade de aprendizagem por meio da mediação na educação infantil. $O$ texto discute um percurso de mediação que possibilita uma multiplicidade de ações para a compreensão da aprendizagem que parte do interesse da criança. A criança no processo de mediação é envolvida por relações indiretas, ou seja, uma ação mediada pelo meio para realizar alguma atividade. A discussão aponta que o ambiente para a criança na educação infantil tem múltiplas aprendizagem a partir de situações mediadas por signos, instrumentos e sujeitos mais experientes, no qual possibilita a construção do conhecimento na ampliação das experiências tornando as crianças sujeitos ativos de sua aprendizagem.

Palavras-chave: Mediação; Aprendizagem; Educação Infantil.

\section{ABSTRACT}

Child education favors a learning context for the child when it enables a process of mediation. Mediation in education is intervention that establishes intermediary relationships for learning. The work is a bibliographical essay that discusses in the work of Lev Vygotski the process of mediation in education and in children's authors the possibility of learning through mediation in early childhood education. The text discusses a course of mediation that allows a multiplicity of actions for the 




ISSN: 1984-6444 | http://dx.doi.org/10.5902/1984644436248

understanding of the learning that departs from the interest of the child. The child in the process of mediation is involved by indirect relationships, that is, a mediated action to perform some activity. The discussion points out that the environment for the child in early childhood education has multiple learning from situations mediated by signs, instruments and more experienced subjects, in which it enables the construction of knowledge in the expansion of the experiences making the children active subjects of their learning.

Keywords: Mediation; Learning; Child education.

\section{Introdução}

A mediação, na educação infantil, representa possibilidade de aprendizagem para a participação da criança no processo de interação social e cultural. A mediação discutida pela teoria histórico cultural desenvolvida por Lev Vygotski alicerça meios de aprendizagem no processo de intervenção que compõe um elemento intermediário na relação mediada que serve como elo na atividade da criança (VYGOTSKI,1978).

A criança aprende quando é protagonista da construção do seu conhecimento e para que isso aconteça necessita de um ambiente que possibilite situações mediadas para a participação e relações cognitivas. Vygotski ${ }^{1}$ (1995) em sua obra discute que a criança não é um ser em espera do desenvolvimento por meio da maturação biológico para aprendizagem, mas levanta o contraponto de que a criança aprende por meio de processos mediados a partir de possibilidades no contexto sócio cultural.

Assim, o presente ensaio tem a intenção de discutir a mediação como possibilidade de aprendizagem na educação infantil fundamentada no teórico Lev Vygotski (1978, 1991, 1995, 1996, 2001, 2007). Trata-se de um estudo teórico bibliográfico, de cunho hermenêutico, que busca nas obras de Vygotsky e outros teóricos da infância como Tizuko Kishimoto (2007), Janet Moyles (2002, 2010), Júlia Oliveira-Formosinho $(2007,2011)$ a compreensão da mediação para a educação infantil. 


\section{FTusy

ISSN: 1984-6444 | http://dx.doi.org/10.5902/1984644436248

\section{A mediação na educação}

O processo de mediação, na educação, impulsiona o aprendizado da criança a tornando protagonista na construção do conhecimento. Para Vygotski (1978), mediação é o processo de intervenção de um elemento intermediário numa relação que deixa de ser direta e passa a ser mediada por elementos que servem como mediadores na atividade da criança.

No decorrer do processo educacional da criança, as relações mediadas passam a predominar sobre as relações diretas (VYGOTSKI, 1995). Dessa forma, a relação do ser humano com o mundo não é uma relação direta, mas, fundamentalmente, uma ação mediada pelo meio, ou seja, "a função indireta de um objeto como meio para realizar alguma atividade" (VYGOTSKI, 1978, p. 44).

Para Daniels (2003), a ideia de mediação envolve várias implicações significativas relacionadas à orientação pedagógica. Entende-se de forma mais ampla que a mediação auxilia na interação do sujeito e na compreensão das estruturas de conhecimento. Tal estrutura não depende de um desenvolvimento interno de maturação orgânica. Segundo Vygotski e Rieber (1999), a criança, por meio das possibilidades oferecidas, ou seja, pela mediação, constrói seu conhecimento. Mas como isso acontece?

Entende-se que a criança age em situações que a levam à aprendizagem, no cotidiano de suas relações, na medida em que ela interage com as pessoas ou com os artefatos da cultura ${ }^{2}$. Por exemplo, uma criança que se encontra em processo de aprender a falar, quanto mais o adulto conversa, canta, dialoga, no momento que realiza as atividades de cuidado, como alimentação e higiene pessoal, mais a criança tem possibilidades de aprender, pela interação, um número maior de palavras e de desenvolver diálogos com o adulto. Entretanto, uma criança, da mesma idade, que está distante dessas possibilidades de aprendizagem pela interação tardará mais a desenvolver a fala.

Outro exemplo é a criança com idade entre 3 a 5 anos que manuseia instrumentos eletrônicos com facilidade, pela observação que realiza do adulto ou sob sua orientação, e que, posteriormente, apresenta mais facilidade em experimentar os 


\section{Tinn Allloahá}

ISSN: 1984-6444 | http://dx.doi.org/10.5902/1984644436248

botões, associando a função à medida que os aperta. A criança envolvida por um artefato cultural, com apoio de um adulto, associa o signo à sua função. Essas possibilidades desencadeiam a construção de um conhecimento precoce, que talvez só fizessem parte do universo da criança anos depois, na idade entre 6 a 10 anos. Mas observa-se, nos tempos atuais, que as crianças muito pequenas conseguem ligar, desligar e executar funções de forma correta em aparelhos eletrônicos, como televisão, celulares e tablets.

Desta forma, Vygotski (VINHA; WELCMAN, 2010) discute em sua teorização a importância do meio no processo de desenvolvimento da criança. $O$ autor afirma que existe aprendizagem "quando o desenvolvimento da criança consiste gradativamente na ampliação de seu meio" (VINHA; WELCMAN, 2010, p. 683). Ainda segundo o autor, o meio é ampliado conforme a vivência de novas relações entre "a criança e as pessoas" que tornam possíveis as diversas formas de relações.

Tal ampliação é uma consequência do que a criança vivencia no meio, pois este "exerce uma ou outra influência, diferente em idades diferentes, porque a própria criança se modifica, assim como se modifica sua relação para com aquela situação" (VINHA; WELCMAN, 2010, p. 691). O meio exerce essa influência pela vivência da criança, ou seja, "de acordo com o que a criança elaborou na sua relação interior para com um ou outro elemento, para com essa ou aquela situação no meio" (VINHA; WELCMAN, 2010, p. 691). Assim, entende-se que o meio determina níveis de desenvolvimento de acordo com o grau de compreensão da criança acerca dessa vivência.

Assim, para Vygotski (1995, p. 229), a criança "não espera se desenvolver para aprender algo, mas por meio da mediação impulsiona sua aprendizagem a partir do momento em que se estabelecem as possibilidades de aprender nas experiências significativas" que vivencia no meio. Com base nessa compreensão, o autor rejeita três concepções que explicam a relação sobre desenvolvimento e aprendizagem. A primeira defende que o processo de desenvolvimento é independente da aprendizagem da criança, no qual o aprendizado é externo ao desenvolvimento. A segunda compreende que o aprendizado e o desenvolvimento são dois processos simultâneos na educação da criança. A terceira pondera que o desenvolvimento 


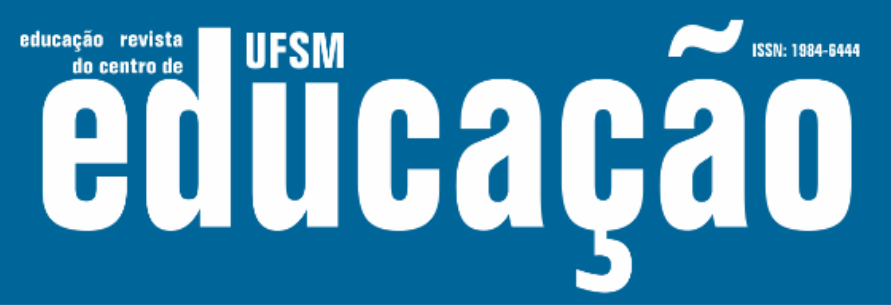

ISSN: 1984-6444 | http://dx.doi.org/10.5902/1984644436248

depende da maturação e do aprendizado (VYGOTSKI, 1978). Mas, para Vygotski (1995, p. 230), "o aprendizado não é o produto do desenvolvimento, mas o impulsiona por meio dos processos mediados que são vivenciados pelo meio".

Nessa perspectiva, a criança é vista com capacidade desde o seu nascimento, está em constantes processos de educação, e nisso a mediação é fundamental, pois colabora significativamente para alavancar a aprendizagem da criança que é vivida pelo meio. Vygotski (VINHA; WELCMAN, 2010) ainda conclui que

[...] o meio não pode ser analisado por nós como uma condição estática e exterior com relação ao desenvolvimento, mas deve ser compreendido como variável e dinâmico. Então o meio, a situação de alguma forma influenciam a criança, norteia o seu desenvolvimento. Mas a criança e seu desenvolvimento se modificam, tornam-se outros. E não apenas a criança se modifica, modifica-se também a atitude do meio para com ela, e esse mesmo meio começa a influenciar a mesma criança de uma nova maneira. Esse é um entender dinâmico e relativo do meio - é o que de mais importante se deve extrair quando se fala sobre o meio na pedologia (VINHA; WELCMAN, 2010, p. 691).

Dessa forma, é importante possibilitar os desafios para a construção de conhecimento, ou seja, proporcionar cada vez mais experiências significativas que irão ajudar a criança a estar em uma "zona de possibilidades intelectuais próprias" (VYGOTSKI, 1995, p. 239). O sentido da experiência significativa para a criança, na teorização de Vygotski (2007), pode ser entendido como o da experiência plena designado por Dewey (1976), na qual a criança vive a experiência para a construção do seu conhecimento. A criança, ao adquirir um número maior de experiências, tem a possibilidade de criar um repertório mais amplo de estruturas para o conhecimento, ou seja, quanto mais se possibilitam experiências significativas a uma criança, maiores serão suas possibilidades de criação, pois "quanto mais rica a experiência humana, tanto maior será o material que dispõem" para sua aprendizagem (VYGOTSKI, 2007, p. 17).

A partir do momento em que se oferece as experiências para as crianças, proporciona-se a elas situações que podem enriquecer suas estruturas intelectuais. Entretanto, entende-se dessa forma que não basta oferecer as experiências para as crianças, elas precisam ser significativas para a construção de suas estruturas intelectuais nas quais a mediação é o elo que as fortifica. Para Del Río e Álvarez 


\section{Tinn Allloahá}

ISSN: 1984-6444 | http://dx.doi.org/10.5902/1984644436248

(2007), esse fortalecimento representa a possibilidade da mediação a partir das experiências significativas para a criança no sentido de criar os meios auxiliares para a compreensão das relações.

A mediação, para Vygotski e Luria (2007), integra a utilização simbólica dos signos e dos instrumentos, incluindo nesse processo a interação colaborativa das pessoas. Vygotski e Luria (2007, p. 68) afirmam que na mediação simbólica "existem os instrumentos materiais (objetos externos) e os instrumentos psicológicos (os signos)", os quais são meios auxiliares que servem como mediadores na educação infantil. Esses instrumentos auxiliam a aprendizagem da criança, principalmente nas funções psicológicas superiores de pensamento, tais como a atenção voluntária, a memorização ativa, o pensamento abstrato, o comportamento intencional, a percepção direcionada e a ação conscientemente controlada.

Del Río e Álvarez (2007, p. 9), no prólogo do livro de Vygotski e Luria (2007) El instrumento y el signo en el desrrollo del niño, no capítulo Una introducción evolutiva a la teoria de la mediación, afirmam que "o modelo de mediação redefine portanto a concepção do sistema psíquico funcional" da criança no qual a mediação simbólica (signos e instrumentos) auxilia na capacidade das representações. Para Vygotski e Luria (2007, p. 10), a representação não é outra coisa a não ser uma apresentação mediada, ou seja, "uma reapresentação" que a criança internaliza e simultaneamente utiliza nas suas estruturais intelectuais.

A criança, em contato com os artefatos da cultura, controla voluntariamente sua atividade psicológica e amplia suas experiências (VYGOTSKI, 1995). Assim, os signos servem como um mediador na aprendizagem das crianças. Para Vygotski (1995, p. 145), "o signo constitui-se em um instrumento psicológico orientado para o próprio sujeito, para dentro do indivíduo"; dirige-se ao controle de ações psicológicas, seja do próprio indivíduo, seja de outras pessoas. "Os signos são elementos que lembram ou simbolizam algo; são marcações que ajudam a memorizar e têm a função significativa, criada culturalmente" (VYGOTSKI, 1978, p. 44).

"O uso de signos serve como meios auxiliares para solucionar um dado problema psicológico" (VYGOTSKI, 1978, p. 47), como, por exemplo, lembrar-se de uma data de aniversário, comparar coisas diferentes ou iguais, relatar um 


\section{Tinn Alloahao}

ISSN: 1984-6444 | http://dx.doi.org/10.5902/1984644436248

acontecimento, escolher usando atributos ou cores. Para Vygotski e Luria (2007), o signo age como um instrumento de atividade psicológica, de maneira análoga ao papel de um instrumento, no trabalho. A partir desse entendimento, a mediação por meio dos signos auxilia no processo de aprendizagem da criança.

Compreende-se que os signos orientam a construção do conhecimento da criança e possibilitam a aprendizagem, internamente ${ }^{3}$, pois, "se o ambiente está permeado pelos signos, a criança pode utilizá-lo como instrumento psicológico", ou seja, os signos ajudam a criança a compreender as relações lógicas abstratas, na construção do conhecimento (VYGOTSKI, 2001, p. 90-91). A criança, quando está aprendendo os números já sistematizados pela cultura, utiliza-se de objetos como pauzinhos, bolinhas, algo que simbolicamente representa a quantidade do número que, posteriormente, internaliza-se por sua representação.

Cita-se também que, na aprendizagem da criança, a fala, como um signo, auxilia no processo de sua compreensão. Para Vygotski (1978), a fala possibilita o momento de maior significação no aprendizado da criança, pois dá origem às formas puramente humanas de inteligência prática e abstrata, que acontece quando a fala e a atividade prática, que se encontram em duas linhas completamente independentes, agora convergem, possibilitando a compreensão da criança. A fala e a ação da criança, na resolução de problemas, fazem parte da mesma função psicológica complexa. Assim, Vygotski e Luria (2007) afirmam:

[...] as crianças resolvem suas tarefas práticas com a ajuda da fala, assim como dos olhos e das mãos. Essa unidade de percepção, fala e ação, que, em última instância, provoca a internalização do campo visual, constitui o objeto central de qualquer análise da origem das formas caracteristicamente humanas de comportamento (VYGOTSKI E LURIA, 2007, p. 32).

Entende-se que a capacidade de falar, ou seja, de se expressar especificamente é uma ação humana, habilita a criança a utilizar a fala como um instrumento psicológico (o signo), na solução de suas tarefas, a superar uma ação impulsiva, a planejar uma solução para um problema antes de sua execução e a controlar seu próprio comportamento (VYGOTSKI, 1978). 


\section{Tinn Ellloará}

ISSN: 1984-6444 | http://dx.doi.org/10.5902/1984644436248

Para Vygotski e Luria (2007),

[...] signos e palavras constituem para as crianças, primeiro acima de tudo, um meio de contato social com outras pessoas. [...] E posteriormente, as funções cognitivas e comunicativas da linguagem tornam-se, então, a base de uma forma nova superior de atividade nas crianças (VYGOTSKI E LURIA (2007, p. 32-33).

Tais funções, favorecidas por meio da fala, possibilitam à criança o processo de aprendizagem, pois a fala torna-se uma ferramenta cultural utilizada pela criança. Essa ferramenta "enriquece e estimula o pensamento e, por meio dela, a mente da criança é reestruturada, reconstruída" (VYGOTSKI; LURIA, 1996, p. 213).

A fala possibilita à criança superar limitações na compreensão de seu ambiente e, uma vez internalizada, torna-se uma parte profunda e constante dos processos psicológicos superiores, os quais ajudam a criança na organização, na unificação e na integração de aspectos variados do comportamento, os quais envolvem percepção, memória, atenção e solução de problemas (VYGOTSKI, 1995).

Outra forma de mediação utilizada é por meio dos instrumentos, que auxiliam a criança na realização de suas tarefas. São elementos externos ao indivíduo, construídos fora dele; sua função é provocar mudanças e controlar processos da natureza, que podem ser identificados nas ações das pessoas (VYGOTSKI; LURIA, 2007).

Os instrumentos são objetos ou elementos que possuem uma utilidade prática, os quais a criança pode usar para a construção de suas experiências. É "um condutor de influência humana sobre o objeto da atividade", que faz a diferença quando possibilitado à criança no seu processo educativo (VYGOTSKI, 1978, p. 55).

Sua utilização possibilita que a criança use o pensamento reflexivo na realização de suas atividades, auxiliando na construção do conhecimento. Por exemplo, a criança imagina que viaja em um trem; na utilização dos materiais, organiza as cadeiras na sala para formar um trem, realizando seu pensamento, ou o desenha com o auxílio de lápis e tinta, mas também pode modelar ou, simplesmente, montar um trem com blocos lógicos. O importante é que tenha à sua disposição os instrumentos para a realização de seu trem que, ao ter significado, possibilitará a construção de sua história. 


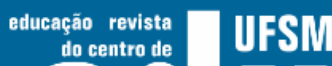 Filloará}

ISSN: 1984-6444 | http://dx.doi.org/10.5902/1984644436248

Assim, considera-se que o uso dos materiais é essencial na educação da criança, principalmente quando se possui uma diversidade que atenda à construção de conhecimento dela. A mediação por meio do instrumento, ou seja, dos materiais, auxilia as crianças nas atividades práticas, o que, reflexivamente, possibilita a elas viverem suas experiências, pois estão em uma relação mediada (VYGOTSKI; LURIA, 2007).

Também a mediação acontece entre os sujeitos, nas interações com um adulto ou uma criança mais experiente, em situações nas quais se busca apoio para solucionar problemas ou dificuldades (VYGOTSKI, 1995). Essa mediação acontece quando há um clima democrático, que propicia ações colaborativas entre as crianças, que aprendem umas com as outras, incluindo nesse processo o adulto responsável pelo grupo.

A criança, quando é favorecida por uma atividade, em colaboração com um adulto ou um colega mais experiente, é envolvida por uma multiplicidade de possibilidades de aprendizagem. A criança supera suas dificuldades durante uma situação colaborativa, pois "resulta mais forte e mais inteligente de que quando atua sozinha" (VYGOTSKI, 1995, p. 240). A mediação que envolve a colaboração é, para a criança, desafiadora e favorece seu crescimento intelectual. Mas qual o papel do adulto na mediação da criança?

$O$ adulto tem um importante papel no processo de mediação, pois a ele cabe a função de favorecer uma prática que envolve interações colaborativas entre as crianças. Tem a função de perceber quais os instrumentos e os signos que proporcionam ações enriquecedoras no ambiente educativo, possibilitando a troca de experiência, a colaboração e o auxílio necessário para a realização das atividades.

O adulto também é o mediador direto da ação da criança, é o parceiro mais experiente e colabora no processo de construção de conceitos e de aquisição de novas experiências. Atua como mediador a partir do momento que observa a experiência da criança e possibilita a sua continuidade, favorecendo múltiplas possibilidades de aprendizagem. Para Vygotski (1991), o professor é o organizador do meio educativo social, instiga a interação desse meio com cada criança. Essa construção é dialética e proporciona experiências significativas. 


\section{T usen Ellibará}

ISSN: 1984-6444 | http://dx.doi.org/10.5902/1984644436248

As atividades de cooperação que orientam a criança são essenciais para a construção de conhecimento. Pela colaboração, a criança encontra-se em uma zona de possibilidades, chamada de Zona de Desenvolvimento Proximal (ZDP) ${ }^{4}$, que favorece a aprendizagem e que se constitui um dos conceitos mais importantes na teoria de Vygotski (1995).

A Zona de Desenvolvimento Proximal (ZDP) indica o que a criança consegue fazer com a ajuda do adulto ou de um colega mais experiente. Para Vygotski (1995, p. 239), "as crianças podem fazer sempre mais e resolver tarefas mais difíceis em colaboração sob a direção ou ajuda de alguém, do que estaria fazendo sozinha". Essas crianças são favorecidas por um universo de possibilidades que auxilia em sua aprendizagem.

Para explicar melhor essas possibilidades de aprendizagem por meio da mediação, Vygotski (1995, p. 242) analisou duas crianças que participaram de um experimento em que as possibilidades de mediação eram distintas, mas a idade intelectual e cronológica delas era a mesma. A primeira criança foi "estimulada e recebeu assistência sendo desafiada" nas atividades, já a segunda não recebeu apoio. A primeira criança respondeu melhor às expectativas, pois, em colaboração, pôde trocar ideias, sendo possibilitada pela mediação. O autor demonstrou que a capacidade de crianças com iguais níveis de desenvolvimento mental para aprender, sob a orientação de um professor, variava enormemente, pois, com a intervenção, uma delas passou a ter idade mental superior, e o curso subsequente de seu aprendizado tornou-se, obviamente, diferente.

A possibilidade de mediações determina a zona de desenvolvimento proximal e favorece a criança a avançar em seu aprendizado (VYGOTSKI, 1995). O processo interno de construção de conhecimento da criança está ligado à trajetória de sua aprendizagem. A oferta de informações e os instrumentos necessários a uma criança oferecem maior possibilidade de construção do conhecimento do que aquela que não está envolvida por essas possibilidades, em seu processo educativo.

A zona de desenvolvimento proximal oferece à criança possibilidades de avançar e de contribuir significativamente para a construção de seu conhecimento. É fundamental propor desafios e possibilitar diversas formas de interação, para que 


\section{T usen Filloará}

ISSN: 1984-6444 | http://dx.doi.org/10.5902/1984644436248

possa ter condições de avançar na construção de seu conhecimento, a partir da troca de experiências (VYGOTSKI, 1995). A criança tem uma gama de condições de estar, constantemente, no nível da zona de desenvolvimento proximal, quando vivencia contextos educacionais em que existem possibilidades de troca de experiências, de manipulação de objetos, de interação com os colegas mais avançados, de discussão dos problemas, de tentativas de experimentar e de discutir o processo da experimentação e, ainda, de dividir suas dúvidas, anseios e perspectivas com outros colegas acerca do que vivencia no espaço educacional.

As atividades que envolvem o grupo, as tarefas em que as crianças interagem fora da escola com seus familiares, os diálogos com os adultos e as resoluções de tarefas em pares possibilitam uma maior abrangência da construção de conhecimento das crianças. Isso "significa que a atividade humana dentro ou fora da escola é essencial para o processo de aprendizagem da criança" (VYGOTSKI, 2001, p. 80).

Para compreender tal processo, Vygotski (2001) desenvolve estudos sobre a atividade humana, um dos mais importantes conceitos na abordagem históricocultural. Esse conceito define que "a atividade representa a ação humana que mediatiza a relação entre o homem, sujeito da atividade, e os objetos da realidade, dando a configuração da natureza humana" (VYGOTSKI, 2001, p. 90), que no desenvolvimento dos processos psicológicos superiores tem sua origem nas relações sociais do indivíduo no contexto social e cultural.

A partir desse conceito, sob a liderança de Leontiev (1995), formulou-se a teoria da atividade, que mediatiza a relação entre a criança e a realidade objetiva. $A$ criança não reage mecanicamente aos estímulos do meio, ao contrário, por meio de sua atividade, põe-se em contato com os objetos e fenômenos do mundo circundante, atua sobre eles e transforma-os, modificando também a si mesmo.

Para Leontiev (1995), a atividade é a interação da criança com o meio. Entende-se que cada organismo realiza a sua própria vida através da sua atividade, a partir do momento que entra em ação com o meio. A criança, nesse processo, é sujeito da sua própria vida. Assim, compreende-se que "a atividade humana tem uma qualidade social, quer dizer, com ela os indivíduos realizam sempre relações sociais 


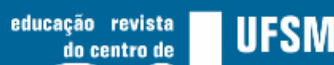 Ellibahá}

ISSN: 1984-6444 | http://dx.doi.org/10.5902/1984644436248

com a realidade, com os outros indivíduos e consigo mesmo" (FICHETNER, 2010, p. 77).

Davydov (1999), em estudo mais alargado sobre a teoria da atividade, afirma que é importante para o desenvolvimento das tarefas, ações e operações o elemento primordial, o desejo, que considera o núcleo básico de uma necessidade. $O$ autor acredita que o desejo deve ser considerado como um elemento da estrutura da atividade, que "as crianças reproduzem o processo real pelo qual os indivíduos criam conceitos, imagens, valores e normas" (DAVYDOV, 1988, p. 22). Diante desse processo, o ensino de todas as matérias na escola deveria ser "estruturado de modo que reproduza, de forma condensada e abreviada, o processo histórico real da geração e desenvolvimento dos conhecimentos" (DAVYDOV, 1988, p. 22), mas sempre incluindo o desejo, a ação que integra a necessidade da criança e a estrutura da atividade.

Compreende-se que o processo de desenvolvimento depende de uma atividade cognitiva inseparável do meio cultural. Isso caracteriza o processo de internalização das funções mentais. Ainda, Davydov (1988) postula que o caráter ativo da aprendizagem e da educação se constitui numa forma específica de atividade da criança, que inclui a parceria adulto-criança e criança-criança nas relações com o meio. Vygotski (2001) afirma que é importante considerar que a criança não se desenvolve por um processo mecânico em etapas, mas pela atividade que estrutura a lógica do pensamento.

Desta forma, a mediação que se estabelece por signos, instrumentos e sujeitos tem seu sustentáculo na atividade que medeia a relação da criança com o meio. Tal relação somente é possível quando existir a atividade humana realizada pela própria criança, conduzida por seu desejo, fruto de uma necessidade de buscar a informação.

\section{A mediação na educação infantil: possibilidades de aprendizagem}

Vygotski (1995) e Vygotski e Luria (2007) assinalam grandes possibilidades de aprendizagem na educação, por meio dos processos de mediação. A educação 


\section{Tinn Ellloahá}

ISSN: 1984-6444 | http://dx.doi.org/10.5902/1984644436248

resulta dos processos de mediações da cultura (signos e instrumentos) e inclui a interação dos sujeitos (criança e adulto).

No contexto da educação infantil, tais processos são favorecidos quando se tem clareza do estabelecimento de uma educação com finalidades democráticas, na participação da criança, que se contrapõe à instrução da pedagogia transmissiva que precisa "instruir ou ensinar alguma coisa diretamente para todos, todos os dias" (MOYLES, 2002, p. 101).

Para Moyles (2002), é necessário ter uma relação de mediação na aprendizagem das crianças, assim concebe que

[...] o professor é o iniciador, o mediador, e o provedor da estrutura dentro da qual as crianças podem explorar, brincar e assumir a responsabilidade por sua aprendizagem, isso faz as coisas ficarem muito diferentes. Mais importante, esta abordagem certamente libera os professores para passar mais tempo com as crianças. O professor se torna um organizador efetivo da situação de aprendizagem, na qual ele reconhece, afirma e apoia as oportunidades para a criança aprender à sua própria maneira, em seu nível e a partir de suas experiências passadas (conhecimentos prévios) (MOYLES, 2002, p. 101).

A partir desse entendimento, a criança, na educação infantil, participa de sua aprendizagem e tem o apoio do adulto como colaborador que auxilia ou favorece situações, nas quais as crianças interagem com outras mais experientes, seja no seu agrupamento ou com o agrupamento subsequente. Também o professor é o mediador responsável pela estrutura que favorece sua aprendizagem. Tal estrutura possibilita que a criança seja mediada por meio dos signos e instrumentos, ao entrar em contato, pela interação, com as brincadeiras e pelas diversas experiências.

No contexto da educação infantil, os signos são utilizados em práticas, tais como contar os pontos na brincadeira de acertar, marcar a data na agenda, conferir o dia no calendário ou nas páginas dos livros de histórias, comparar as diversas formas das letras e identificar o som de cada uma delas, pronunciando as palavras das histórias. Essas práticas mediadas por signos auxiliam na compreensão dos processos de construção de conhecimento das crianças.

O ambiente rico na diversidade dos signos (tais como letras, números, anúncios, versos, rótulos, palavras, frases, jogos de cartas, dominó e bingo) favorece a criança a fazer suas relações, internalizando-os a partir do momento em que entra 


\section{Authapão}

ISSN: 1984-6444 | http://dx.doi.org/10.5902/1984644436248

em contato com esses artefatos da cultura. Um exemplo dessa natureza é a aprendizagem de conceitos matemáticos, por meio do brincar com signos. As crianças brincam de fazer coleções e, nesse processo, vão internalizando a estrutura de contar, estabelecendo, na coleção, as relações de quantidade de mais ou de menos. A prática de contar pode ser mediada pelo adulto, ao propor à criança que faça o registro das quantidades em um bloco de anotações, assim, as crianças podem marcar por dia, por semana ou por mês quantos objetos chegaram a mais, em suas coleções (GRIFFITHS, 2006).

Dessa forma, o que se favorece à criança, na educação infantil, por meio da mediação em contato com os signos, é a linguagem simbólica. Tal linguagem inclui o sistema de contar, o sistema da linguagem escrita, os sistemas simbólicos algébricos, os diagramas, os mapas, os desenhos e outros sinais convencionais com os quais a criança está em contato, por meio da cultura (VYGOTSKI, 1978). Mas a mediação é significativa quando se organizam as experiências, para que a criança possa estar em contato com as diversas linguagens, no auxílio de sua aprendizagem.

Já a mediação no uso do instrumento, na educação infantil, favorece a organização de um ambiente, na diversidade de materiais, o que possibilita à criança enriquecer suas experiências. Para Dewey (1959), Malaguzzi (1999), OliveiraFormosinho (2011) e Moyles et al. (2010), o ambiente é facilitador para a aprendizagem da criança.

Malaguzzi (1999) considera o ambiente como o segundo educador para a aprendizagem da criança, no sentido de enriquecer suas experiências. Uma criança que brinca com uma boneca terá uma criatividade mais enriquecida, caso tenha à sua disposição mamadeiras, roupas infantis, remédios, fraldas, enfim, acessórios que favoreçam a brincadeira de mãe e filha. A criança tem a possibilidade de aprendizagem quando os materiais são diversificados em seu cotidiano, promovendo situações em que possa viver a experiência, criando e recriando nas suas ações.

Dewey (1959) propõe em suas ideias pedagógicas uma estrutura de um ambiente onde a criança possa interagir e participar, pois em sua época as escolas eram estruturadas para as crianças ouvirem atentamente, e não para participarem. Da mesma forma, Oliveira-Formosinho e Formosinho (2011) afirmam que o ambiente 


 Ellibahao}

ISSN: 1984-6444 | http://dx.doi.org/10.5902/1984644436248

é uma estrutura que deve propiciar a participação da criança no uso de materiais diversos que podem ser estruturados e não estruturados.

Para Moyles (2002) e Moyles et al. (2010), é importante que a criança possa usar materiais estruturados e não estruturados, tendo à sua disposição opções para viver suas experiências, principalmente quando essas envolvem o brincar. A criança, por meio das interações, aprende a brincar de outras formas e ensina novas brincadeiras, em uma troca mútua de aprendizagem.

É interessante que a criança tenha, na área do parque, uma casinha de boneca estruturada, pois no seu interior pode criar situações que envolvem uma relação familiar, se tiver à sua disposição materiais que propiciem estender roupas, cuidar dos filhos, limpar a casa (MOYLES, 2002). Mas a disponibilidade de materiais não estruturados, como tecidos de diversos tamanhos, cores e espessuras, possibilita a criação de cabanas, acampamentos e túneis, ampliando sua imaginação e suas experiências.

A mediação por meio dos instrumentos consiste em oferecer a diversidade de materiais e, pela observação, em reorganizar os espaços conforme o interesse das crianças. Ressalta-se que observar as crianças é fundamental para se organizar os espaços e criar novas situações de aprendizagem, que partem de seus projetos. Oliveira-Formosinho (2011), ao referir-se à organização das áreas de experiências para as crianças, cita que as professoras ofereceram livros sobre a diversidade cultural e alguns acessórios específicos da China para as crianças que estavam interessadas na cultura chinesa. A consequência dessa mediação foi o interesse pelas culturas de outros países, ampliando a experiência que teve início com a cultura da China. A mediação, além de envolver outras situações, teve a organização do ambiente favorecido pelos materiais, para apoiar a aprendizagem da criança.

Entende-se que a prática de mediar precisa ter um olhar para a criança, no contexto de suas experiências, para ampliá-las, possibilitando a aprendizagem da qual a criança faz parte, como membro decisivo. Dessa forma, a mediação inclui a interação do adulto e de uma criança mais experiente, na colaboração das atividades.

O ponto central para mediar pela interação direta dos sujeitos, na educação infantil, é conceber o ambiente educativo como um processo em que todos os 


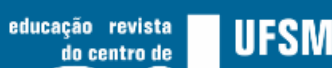 Allibahá}

ISSN: 1984-6444 | http://dx.doi.org/10.5902/1984644436248

envolvidos são agentes, em construção de conhecimento (OLIVEIRA-FORMOSINHO; KISHIMOTO; PINAZZA, 2007; OLIVEIRA-FORMOSINHO, 2011; HEDEGAARD, 1996).

Para Hedegaard (1996), o ambiente educativo que envolve uma relação de interação dos grupos, pares de crianças e adultos - que não necessariamente precisa ser o professor do grupo, mas as pessoas que fazem parte da escola e, principalmente, a família - tem um potencial maior de aprendizagem na diversidade de situações, o que favorece às crianças aprenderem umas com as outras e também com os adultos.

Na educação infantil é preciso criar as situações em que as relações existem, pois, pela interação, as experiências são ampliadas. Segundo Whitebread (2010), é preciso propiciar trabalhos de grupos envolvendo as crianças em atividades colaborativas, que possibilitem articular seus entendimentos, avaliar seu próprio desempenho e refletir sobre sua aprendizagem. Uma prática interessante consiste em estabelecer, nos agrupamentos, monitorias, nas quais as crianças auxiliam umas às outras, em algumas tarefas orientadas pela professora. Também é importante dar tempo para as crianças encontrarem as soluções para seus problemas e, assim, aprenderem mutuamente.

\section{Considerações finais}

A mediação é um processo de intermediário que possibilita a aprendizagem da criança por meio de signos, instrumentos e sujeitos mais experientes. As práticas de mediações, possibilitadas pelo apoio do adulto, favorecem uma multiplicidade de aprendizagens no contexto da educação infantil que amplia as experiências das crianças.

Os estímulos oferecidos, para que ocorram as experiências, propicia às crianças um pensar reflexivo e desafiador, para que tenham iniciativas na construção de conhecimento e na investigação de suas próprias hipóteses, com autonomia na tomada de decisões. 




ISSN: 1984-6444 | http://dx.doi.org/10.5902/1984644436248

Assim, as práticas pedagógicas de um profissional da educação são essenciais para que as ações mediadoras possibilitem o envolvimento da criança para a construção do conhecimento, na direção da continuidade das experiências, uma vez que os elementos mediadores favorecem situações de aprendizagem.

A criança mediada por situações tem a capacidade de conectar relações cognitivas para a aprendizagem sem que esteja a espera de maturação biológica, pois o trabalho de Vygotski (1995) nos mostra que a aprendizagem que impulsiona o desenvolvimento da criança. A criança em um ambiente mediado amplia as experiências e passa a ser a protagonista de sua aprendizagem, ou seja, um sujeito ativo que constrói conhecimento.

\section{Referências}

DANIELS, Harry. Vygotsky y pedagogía. Barcelona: Paidós Ibérica, 2003.

DAVYDOV, Vasily Vasilovich. Problems of developmental teaching: the experience of theoretical and experimental psychological research - excerpts. Soviet Education, New York, v. 30, n. 8-10, ago/out. 1988.

DAVYDOV, Vasily Vasilovich. A new approach to the interpretation of activity structure and content. In: CHAIKLIN, S.; HEDEGAARD, M.; JENSEN, U. J. Activity theory and social practice: cultural-historical approaches. Aarhus: Aarthus University Press, 1999

DEL RÍO, Pablo.; ÁlVAREZ, Amelia. Una introducción evolutiva a la teoria de la mediación. In.: VYGOTSKI, L.; LURIA, A. R. El instumento y el signo em el desarrollo del niño. Trad. de Pablo del Río e Amelia Álvarez. Madrid: Fundación Infancia y Aprendizage, 2007.

DEWEY. John. Experiência e educação. São Paulo: Companhia Editora Nacional, 1976.

DEWEY. John. Democracia e educação: introdução à filosofia da educação. São Paulo: Companhia Editora Nacional, 1959.

FICHTNER, Bernd. Introdução na abordagem histórico-cultural de Vygotsky e seus colaboradores. Alemanha: Universidade de Siegen, 2010.

GRIFFITHS, Rose. A matemática e o brincar. In: MOYLES, J. R. et al. A excelência do brincar. Trad. de Maria Adriana Veríssimo Veronese. Porto Alegre: Artmed, 2006. 


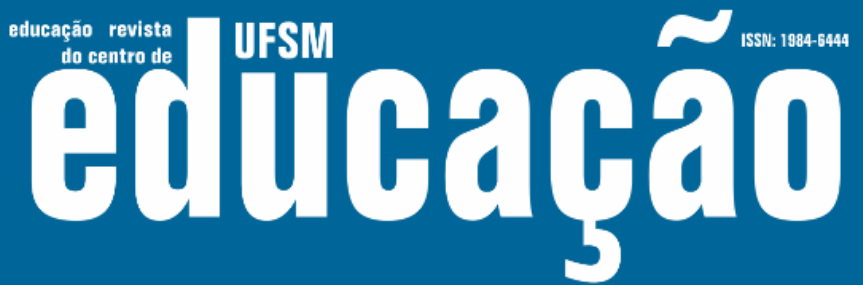

ISSN: 1984-6444 | http://dx.doi.org/10.5902/1984644436248

HEDEGAARD, Mariane. A zona de desenvolvimento proximal como base para a instrução. In: MOLL, L. C. Vygotsky e a educação: implicações pedagógicas da psicologia sócio-histórica. Porto Alegre: Artmed, 1996.

KISHIMOTO, Tizuko Morchida, et al. Jogo, Brinquedo, Brincadeiras e a Educação. São Paulo: Cortez, 2007.

LEONTIEV, Alexis Nikolaevich. 0 desenvolvimento do psiquismo. São Paulo: Moraes, 1995.

MALAGUZZI, Loris. História, ideias e filosofia básica. In: EDWARDS, C.; GANDINI, L.; FORMAN, G. As cem linguagens da criança. Trad. Dayse Batista. Porto Alegre: Artmed, 1999.

MOYLES, Janet. R. et al. Fundamentos da educação infantil: enfrentando o desafio. Trad. de Maria Adriana Veríssimo Veronese. Porto Alegre: Artmed, 2010.

MOYLES, Janet. R. Só brincar? O papel do brincar na educação infantil. Trad. de Maria Adriana Veríssimo Veronese. Porto Alegre: Artmed, 2002.

OLIVEIRA-FORMOSINHO. Júlia (Org.). O espaço e o tempo na Pedagogia-emParticipação. Porto: Porto Editora, 2011

OLIVEIRA-FORMOSINHO, Júlia; KISHIMOTO, Tizuko. Morchida; PINAZZA, Mônica Appezzato. Pedagogia(s) da infância: Dialogando com o passado, construindo o futuro. Porta Alegre: Artmed, 2007.

PRESTES, Zoia Ribeiro. Quando não é quase a mesma coisa: Análise das traduções de Lev Semionovitch Vigotski no Brasil repercussões no campo educacional. Tese (doutorado em Educação). Faculdade de Educação, Universidade de Brasília. Brasília, p.295. 2010.

VINHA, Márcia Pileggi; WELCMAN, Max. Quarta aula: a questão do meio na pedologia, Lev Semionovich Vigotski. Psicologia USP, São Paulo, v. 21, n. 4, 2010.

VYGOTSKI, Lev Semyonovich. Mind in society: the development of higher psychological processes. Cambridge, EUA: Harvard University Press, 1978.

VYGOTSKI, Lev Semyonovich. Problemas teóricos y metodológicos de la psicología. Madri: Machado Libros, 1991. (Obras Escogidas, 1).

VYGOTSKI, Lev Semyonovich. Problemas de psicología general. Madrid: Machado Libros, 1995. (Obras Escogidas, 2).

VYGOTSKI, Lev Semyonovich. Psicologia pedagógica. São Paulo: Martins Fontes, 2001.

VYGOTSKI, Lev Semyonovich. La imaginación y el arte em la infância. Madrid: Akal, 2007. 
